\title{
A pandemia de Covid-19: aspectos do seu impacto na sociedade globalizada do século XXI
}

\section{Covid-19 pandemic: impacts regarding the globalized society in the twenty-first century}

\author{
Luriene Dantas de Macedo ${ }^{1}$ \\ José Roberval Dantas de Macedo ${ }^{2}$
}

\begin{abstract}
Resumo: O ponto de partida deste trabalho é realizar uma discussão sobre a pandemia de Covid-19 e aspectos do seu impacto na sociedade globalizada do século XXI. A ideia é refletir sobre os desafios para vencer a doença, um claro problema social, mas negligenciado pelas políticas neoliberais, em que pese a importância do papel do Estado, da valorização do sistema de saúde pública, das políticas de assistência social, do socorro aos pequenos negócios, entre outras questões. A dominação e o controle do espaço, da natureza física e da vida humana e animal do planeta, expressões do capitalismo, e responsáveis pela destruição das bases que sustentam a relação harmoniosa entre o homem e o meio ambiente, estão sendo desafiadas por influências externas, no caso um vírus com potencial pandêmico, que impactou e deixou o motor da acumulação de capital particularmente vulnerável. Se o momento propicia pensarmos e sonharmos com um mundo melhor, mais justo e sustentável, ambiental, social e economicamente, a realidade sobrepõe os desafios que nos são impostos, como as desigualdades sociais e o desemprego. Assim, é urgente a construção de uma arquitetura político-institucional, uma forte cooperação intra e interpaíses e a valorização da vida de todos os seres (animais e vegetais) pertencentes ao planeta Terra.
\end{abstract}

Palavras-chave: Covid-19. Século XXI. Sociedade industrial e modernizada.

\begin{abstract}
This work aims to discuss issues related to the Covid-19 pandemic and its impact on behalf of the globalized society in the twenty-first century. The work reflects on the necessary challenges made in order to to overcome the disease, which is a clear social problem considering that it has been neglected by neoliberal politics. Thus, the work deals with the importance of the State and its role on the valorization of the public health system, social work policies, financial aid to small businesses, amongst other issues. It is seen that domination and control of space as well as physical nature and human and animal life on the planet are expressions of capitalism. This movement in turn, is responsible for the destruction of the bases that support the harmonious relationship between man and the environment. These issues come forth since they are being challenged by external influences, in this case by a virus with pandemic potential, which affected and led to capital accumulation of particularly vulnerable. If the current times, it allows us to think and dream of a better, fairer, and a more sustainable world either environmentally, socially, or economically. It is possible to acknowledge that reality overlaps and imposes challenges such as social inequalities and

1 Doutora em Economia pela Universidade Estadual de Campinas (UNICAMP). Professora Adjunta da Universidade Federal do Rio Grande do Norte, membro do Grupo de Estudos e Pesquisas em Espaço, Trabalho, Inovação e Sustentabilidade (GEPETIS) e do Laboratório Interdisciplinar Sociedades, Ambientes e Território (LISAT). E-mail: luzienedm@,uol.com.br.

2 Administrador de Empresas. Graduando em Psicologia pelo Centro Universitário do Distrito Federal (UDF). Terapeuta holístico. E-mail: robdm@uol.com.br.
\end{abstract}


unemployment. Thus, there is an urgent need to build a political-institutional infrastructure, strong intra- and inter-country cooperation as well as value life of all beings (animals and plants) belonging to planet Earth.

Keywords: Covid-19. Twenty-first century. Industrialized and modernized society.

\section{Introdução}

A Covid-19 é transmitida pelo vírus da SARS-CoV-2, causador da Síndrome Respiratória Aguda Grave (SARS). Vindo possivelmente do morcego, esse vírus é altamente transmissível entre os humanos e responsável pela atual pandemia, uma enfermidade que, entre outros males provocados, vem afetando o processo de valorização do capital nas economias avançadas e emergentes.

As consequências decorrentes da pandemia que ora assola o mundo inteiro vão além dos aspectos econômicos, pois afetam diretamente, e no mesmo grau de importância, setores relacionados à infraestrutura social, sanitária e de saúde. Em meio a esse quadro patogênico, de enfermidade amplamente disseminada, é urgente a implantação de políticas públicas para evitar o colapso de setores considerados vitais para a sobrevivência humana.

Desde 2003, o mundo vivencia uma escalada no número de infecção de humanos por vírus: H5N1 e H7N9 (2003); SARS no sul da China (2002-2003); gripe aviária em Hong Kong (2003-2004); H1N1, que apareceu no México, sendo declarada pandemia pela OMS (2009-2010); Mers, no Oriente Médio (2012); ebola no oeste da África (2013-2016 e desde 2018) e zika no Brasil (2016). Após essas outras epidemias, surge a segunda pandemia do século XXI, a Covid-19.

Este artigo visa, portanto, discutir a pandemia de Covid-19 e aspectos do seu impacto na sociedade globalizada do século XXI. Para tanto, destaca a relação do novo coronavírus com a evolução da sociedade industrial e modernizada, bem como os aspectos cristalizados e mais severos da pandemia: a necessidade de valorização do sistema de saúde pública e de redefinição do papel do Estado na economia e no desenvolvimento social e ambiental das sociedades nacionais e internacionais.

Assim como as outras pandemias que ocorreram no mundo, em que se destaca a gripe espanhola, em 1918, considerada a pior registrada até os dias atuais, a pandemia atual revela, mais uma vez, o desequilíbrio da relação do homem com a natureza. Ao explorar solos e animais em quantidade escalar visando o lucro, permite-se a transformação do habitat, o uso de defensivos químicos e a mercantilização de tudo que é produzido, manejado, confinado, glomerado e abatido. No capitalismo, tudo é transformado em mercadoria e medido, não pelo que representa para a natureza e para a vida, mas pelo valor de troca. 


\section{A pandemia de Covid-19 e sua relação com a sociedade industrial e modernizada}

A Covid-19 surgiu no fim de 2019. Dados de 07 de julho de 2020 confirmaram 11.950.044 casos e 546.622 óbitos $^{3}$ no mundo. No Brasil, são 1.674 .655 casos e 66.868 mortes. Essa doença já está presente em 213 países. Apresenta uma taxa de letalidade de 4,6\%, no Brasil, cerca de 4\%. Com base nesses números, constata-se que a taxa de mortalidade da Covid-19 é relativamente mais baixa que a da gripe espanhola, estimada entre 10 e 20\%. Trata-se de um vírus nomeado pelo Comitê Internacional de Taxonomia de Vírus (ICTV) de SARS-CoV-2, uma referência à Síndrome Respiratória Aguda Grave (do inglês, Severe Acute Respiratory Syndrome) causada por um novo tipo de coronavírus (CoV-2).

De acordo com Shereen et al. (2020), a taxa de transmissão do SARS-CoV-2 é maior que o SARS-CoV, o primeiro coronavírus, possivelmente devido a um evento de recombinação genética na proteína S na região RBD do SARS-CoV-2, sendo mais transmissível que a gripe comum, com taxa de reprodução entre 2 e 2,5, e a gripe espanhola, que apresentava taxa reprodutiva de cerca de 1,8 (CALLEJA, 2020).

A SARS surgiu em 2002, na província de Guangdong, no sudeste da China, em um mamífero de pequeno porte, chamado de gato almiscarado. Segundo Ujivari (2011), desde a década de 1980, no território chinês, havia uma prática de caçar, capturar e confinar esse animal para suprimento de carne dos restaurantes. Nessas condições, o mamífero se submetia a situações de estresse e debilitação das suas defesas naturais, ocasionando a circulação do vírus, bem como a sua mutação, capaz de infectar células humanas. Os primeiros contaminados foram os trabalhadores dos restaurantes. Hoje os morcegos são considerados os portadores do vírus da SARS, sendo "evidenciada a presença de outros vírus da família da SARS em morcegos da África e América" (UJIVARI, 2011, p. 4).

A epidemia de SARS, em 2003, matou 10\% dos oito mil indivíduos infectados em quase trinta países, alcançando cerca de novecentas mortes. Naquele momento, a OMS deixou as autoridades , a mídia internacional, médicos e outros profissionais de saúde em alerta máximo para tomar decisões que pudessem controlar a epidemia e impedir a sua ampla disseminação. Nesse contexto, destaca Ujivari (2011), formaram uma frente ampla com o objetivo de isolar os indivíduos suspeitos de infecção pelo vírus e evitar a contaminação em massa. O alerta foi importante, visto que serviu para preparar a população e as nações acerca da ocorrência de uma epidemia com potencial de contágio e letalidade preocupantes.

\footnotetext{
${ }^{3}$ https://www.worldometers.info/coronavirus/
} 
Diferentemente da SARS, a gripe suína de 2009, denominada Influenza A (H1N1), causada pelo novo vírus influenza ${ }^{4}$, também bastante temido no mundo, apresentou letalidade de 0,1\%, um total de oito mil óbitos e oito milhões de infectados. Esse vírus se globalizou primeiro em razão da sua natureza, com significativo grau de contágio silencioso. Ou seja, de modo diverso da doença de 2002, cujos sintomas são inicialmente leves, acentuando-se no decorrer dos dias, o paciente infectado com a Influenza A elimina o vírus nas primeiras vinte e quatro horas antes de surgir os primeiros sintomas: febre, dor de garganta, mal-estar e dores pelo corpo (UJIVARI, 2011). Contudo, quando se descobre a infecção, o paciente já transmitiu o vírus para outros indivíduos, no ambiente de trabalho, em casa, entre amigos, familiares etc.

Importante destacar que a forma como nos relacionamos com a natureza, alterando o meio ambiente, destruindo o solo, pântanos, rios, paisagens e domesticando os animais (mantendo-os em cativeiro ou mesmo traficando-os), revela um enorme potencial para o surgimento de vírus, bactérias e outros patógenos. Segundo Harvey (2011, p. 151), "a longa história de destruição criativa da terra produziu o que é às vezes chamado de "segunda natureza" - a natureza remodelada pela ação humana".

Assim, não é de espantar a ideia de que o surgimento desses vírus contagiosos resulte das transformações dos habitats e das agressões às espécies, em favor do acúmulo do capital. Ao longo da história, as consequências sociais e ambientais são consideradas o "desenvolvimento de práticas humanas em relação ao meio físico e à teia da vida ecológica, que mudam a face da terra de maneira muitas vezes dramática e irreversível” (HARVEY, 2011, p. 152).

Ujivari (2011) relata que a gripe suína surgiu no século XIX. Diríamos, portanto, especialmente a partir da segunda Revolução Industrial, quando o progresso da ciência e da técnica trouxe a possibilidade da produção por meio da mecanização da produção em grande escala e/ou confinamento de animais para consumo. Com isso, presenciou-se a transformação do ambiente rural, bem como "[...] o impulso das necessidades especulativas de acumulação adicional (incluindo a especulação sobre a terra) e, só secundariamente, tomando em conta as necessidades das pessoas" (HARVEY, 2011, p. 152).

Os vírus foram surgindo, portanto, em uma lógica que quebrou "a harmonia rural e sua interação entre animais e vegetais" (UJIVARI, 2011, p. 53). Tal movimento cedeu lugar à especialização em plantação de grãos e criação de animais para o abate em quantidades cada vez maiores, visando especialmente o mercado externo. Assim, estimulados pelo aumento da riqueza e, com o objetivo de suprir a grande demanda por carne, muitos indivíduos transformaram o gado, porcos e aves em mercadorias.

\footnotetext{
${ }^{4}$ O mesmo vírus que originou a gripe espanhola de 1918, no qual matou 20 milhões de indivíduos (UJIVARI, 2011).
} 
Considerando que a Revolução Industrial (segunda metade do século XIX e início do século $\mathrm{XX}$ ) trouxe inovações para os setores de comunicação, transporte, energia, química pesada, toda a dinâmica de produção de grãos e criação de animais passou a ser realizada de forma a abranger outros espaços e regiões mais distantes. Entre as novidades estavam os refrigeradores para as embarcações, em 1870, para o transporte de carne refrigerada da América para Europa, os fertilizantes, que substituíram o esterco, e o uso do trator no processo de aração da terra.

A ciência foi não apenas responsável pelas inovações que aumentaram a produção, a produtividade no trabalho e o consumo, mas também pela exploração animal e agrícola "[...] $\underline{\text { e, }}$ sem perceber, reuniria os ingredientes para o nascimento de vários vírus influenza, inclusive o da gripe suína”. (UJIVARI, 2011, p. 51, grifo nosso).

Além da preparação do cenário para a vinda desses vírus, pesa também a nossa atuação como "agentes evolutivos que atuam por meio de todas as coisas, da produção de plantas e animais, da ampla modificação do habitat e do rápido crescimento populacional à difusão e à combinação de espécies em escala global” (HARVEY, 2015, p. 280).

Desse modo, a insistente ameaça de uma nova gripe e pandemias é análoga ao nosso modo de ser e de nos posicionar perante a natureza. Segundo Ujivari (2011), vírus estão surgindo em aves e porcos em razão da intensidade da criação e aglomeração a que se submetem esses animais. O caso da China é emblemático e serve de exemplo para verificarmos de que maneira atuamos contra a força da natureza pelo desejo especulativo e consciente de lucrar por meio da exploração intensiva de animais em confinamento: “em 1968, havia 5 milhões de porcos e 12 milhões de aves domesticadas; hoje, são 500 milhões de porcos e 13 bilhões de aves (UJIVARI, 2011, p. 71).

Em setembro de 2019, o documento do Global Preparedness Monitoring Board (GPMB) ${ }^{5}-A$ Word At Risk - alertou o mundo sobre a necessidade de pensar ações políticas para nos prepararmos para, bem como para mitigarmos os efeitos das emergências globais de saúde. Isso porque o mundo vem sendo confrontado o tempo todo pelo aumento de surto de doenças infecciosas, tais como as doenças virais. A gripe é uma delas. O documento assinala que, entre 2011 e 2018, a OMS acompanhou 1.483 eventos epidêmicos em 172 países. Logo, doenças propensas a epidemias, como gripe, Síndrome Respiratória Aguda Grave (SARS), Síndrome Respiratória no Oriente Médio (MERS), ebola, zika, peste, febre amarela e outras, prenunciam uma era de elevado risco de propagação frequente de surtos cada vez mais difíceis de gerenciar.

\footnotetext{
${ }^{5}$ O Conselho, que se baseia no trabalho da Força-Tarefa e Painel de Crises Globais em Saúde, criada pelo SecretárioGeral das Nações Unidas após a epidemia de Ebola 2014-2016, trabalha independentemente de todas as partes, incluindo seus coorganizadores, para fornecer as avaliações e recomendações mais francas possíveis. (GPMB, setembro 2019).
} 
Por esse motivo, o GPMB chama atenção especialmente para a existência de microrganismos projetados e recriados em laboratórios, causadores de doenças, a despeito de os desenvolvimentos científicos e tecnológicos oferecerem ferramentas capazes de promover a saúde pública (incluindo a avaliação segura de contramedidas médicas).

Dessa forma, o referido Conselho exige mais do que nunca uma liderança política determinada e capaz de se preparar para as ameaças à saúde nos níveis nacional e global. Destacam-se, pois, sete ações urgentes para atender as emergências de saúde (GPMB, setembro 2019, p. 7-10):

1 Chefes de governo devem se comprometer e investir, implementando as suas obrigações vinculativas no Regulamento Sanitário Internacional, de 2005.

2 Os Estados membros do G7, G20 e G77 e organizações intergovernamentais regionais devem cumprir seus compromissos políticos e financeiros de preparação e concordar em monitorar rotineiramente o progresso durante suas reuniões anuais.

3 Todos os países devem construir sistemas fortes e priorizar o envolvimento da comunidade em todos os esforços de preparação.

4 Países, doadores e instituições multilaterais devem estar preparados para o pior e garantir um investimento adequado no desenvolvimento de vacinas e soluções terapêuticas inovadoras.

5 As instituições financeiras, FMI e o Banco Mundial, devem vincular a preparação ao planejamento de riscos financeiros.

6 Os financiadores de assistência ao desenvolvimento devem criar incentivos e aumentar o financiamento para os países mais pobres e vulneráveis por meio de assistência ao desenvolvimento da saúde,

7 O Secretário-Geral das Nações Unidas, com a OMS e o Escritório das Nações Unidas para a Coordenação de Assuntos Humanitários (OCHA), deve fortalecer os mecanismos de coordenação em diferentes países, contextos de saúde e emergências humanitárias.

Não se pode ignorar que a ameaça de uma nova pandemia esteve e continua presente no nosso dia a dia. Conforme se enfatizou anteriormente, em 2003, a epidemia foi controlada e não se transformou em pandemia porque os órgãos de controle criaram uma rede de apoio para conter o seu avanço. $\mathrm{Na}$ execução da política de saúde, destaca-se a informação compartilhada diariamente, uma ação indispensável tanto para conscientizar a população e o poder público da grave ameaça quanto para alertá-los sobre a necessidade de combatê-la eficazmente.

O que essas epidemias/pandemias trazem de lição para atenuar a força com que a Covid19 já se apresenta no mundo, com impactos sociais, econômicos, sanitários, psicológicos e efeitos desastrosos em qualquer contexto político-institucional?

Tomaremos como base os estudos de Barry (2020), Ujivari (2011), Calleja (2020) e Shereen et al. (2020) para elencar algumas dessas lições. Trata-se de tentativas e erros capazes de iluminar nosso aprendizado e a tomada de decisões. 
Primeiro: todas as epidemias e pandemias vieram em ondas;

Segundo: é urgente a descoberta de uma vacina universal, capaz de atacar com efetividade a hemaglutinina ${ }^{6}$, encontrada no vírus que infecta humanos, o influenza. Várias pesquisas estão sendo realizadas, mas não em número suficiente, tendo em vista a carência de recursos e o fato desse aspecto não ser ainda uma das prioridades da pesquisa médica;

Terceiro: deve-se priorizar o investimento em tecnologias para fabricação de vacinas eficazes contra as pandemias e epidemias, sejam elas sazonais ou não. Em 2009, a vacina contra a Influenza A (H1N1) foi importante, a despeito de ter chegado apenas durante a segunda onda.

No caso da Covid-19, Shereen et al. (2020) apontam o nome de diversas empresas que estão trabalhando para o desenvolvimento de vacinas eficazes contra o novo coronavírus: Moderna Therapeutics, Inovio Pharmaceuticals, Novavax, Vir Biotechnology, Stermirna Therapeutics, Johnson \& Johnson, VIDO-InterVac, GeoVax-BravoVax, Clover Biofarmaceuticals, CureVac, e Codagenix. Essas vacinas precisam, no entanto, de um período de três a dez meses para serem comercializadas;

Quarto: existe hoje um sistema de vigilância sanitária muito mais eficaz que o de cem anos atrás. É notória, porém, a necessidade de tornar o sistema de vigilância sanitária uma prioridade dos serviços de segurança, pois é "que dá, o mais rápido possível, o alerta para um vírus com potencial de se tornar pandêmico, acelerando a produção de vacinas" (BARRY, 2020, p. 973);

Sexto: deve ser proibida a utilização de animais selvagens e aves como fontes de alimento (SHEREEN et al., 2020), visto que esses bichos carregam patógenos capazes de infectar alimentos e humanos em larga escala;

Sétimo: é necessário e urgente priorizar a realização de diagnóstico rápido e preciso da Covid-19 em pacientes suspeitos, já que o teste baseado na Reação em Cadeia de Polimerase (PCR) é caro e o resultado demora um pouco mais para ser liberado. Para Shereen et al. (2020), o teste é importante porque os sintomas da Covid-19 são semelhantes aos das influenzas e alergias sazonais. Ou seja, uma pessoa com influenza ou alergia sazonal também pode apresentar temperatura corporal elevada, detectável por medidores térmicos e ser considerada suspeita de Covid-19;

Oitavo: intervenções não farmacológicas, ou seja, sem o uso de remédios, como forma de mitigar o impacto de uma pandemia são importantes para evitar o colapso do sistema de saúde, mas tem utilidade limitada. É o caso do isolamento social completo e da quarentena generalizada, que para ser benéfica, deve ser rígida o suficiente;

\footnotetext{
${ }^{6}$ Para maiores informações, consultar o livro a Grande Gripe, de John M. Barry.
} 
Nono: a higienização das mãos de forma disciplinada, combinada com o uso de máscaras, resulta na proteção daqueles que estão em contato direto com a pessoa doente (BARRY, 2020, p. 979-980);

Décimo: nos hospitais, priorizar o registro de controle de infecção por meio de equipes remuneradas para esse fim. Segundo Barry (2020), o sucesso vai depender do rigor, da ênfase e disciplina;

Décimo primeiro: o uso de máscaras de proteção é eficaz porque impede que gotículas lançadas da boca ou do nariz se espalhem em determinados cômodos. "Um fato comprovado por experimentos em 1918” (BARRY, 2020, p. 979);

Décimo segundo: deve-se priorizar o monitoramento contínuo do vírus para detectar mudanças em seu comportamento, bem como na forma como devemos reagir a ele. A vigilância é primordial antes, durante e após a ocorrência de qualquer pandemia e/ou epidemia (BARRY, 2020), devendo ser considerada uma ação essencial de política pública.

\section{Aspectos do impacto da Covid-19 na sociedade globalizada do século XXI}

Iniciamos o século XXI com uma utopia "postulando a necessidade de buscar um novo paradigma científico, capaz de se substituir ao industrialismo" (VEIGA, 2010, p. 11). A rigor, almejávamos repensar o alcance do desenvolvimento de um país e/ou região tomando-se como base a ideia de sustentabilidade ambiental do crescimento econômico e melhoria da qualidade de vida (VEIGA, 2010). Por isso, começamos a intensificar a ideia de desenvolvimento sustentável, cuja "adjetivação deveria ser desdobrada em socialmente includente, ambientalmente sustentável e economicamente sustentado no tempo" (VEIGA, 2010, p. 10).

Inicialmente, em 2000, estabeleceram-se oito Objetivos de Desenvolvimento do Milênio $(\mathrm{ODM})^{7}$, com alcance em 2015 (NAÇÕES UNIDAS BRASIL, 2000). Em 2015, adotou-se um pacto global entre os países com o objetivo de "acabar com a pobreza, promover a prosperidade e o bem-estar para todos, proteger o meio ambiente e enfrentar as mudanças climáticas" (NAÇÕES UNIDAS BRASIL, 2015), Esse pacto resultou em dezessete Objetivos de Desenvolvimento Sustentável (ODS) ${ }^{8}$, os quais, estabelecidos pela Assembleia Geral das Nações Unidas, e tomando-se como base a Conferência das Nações Unidas sobre Meio Ambiente e Desenvolvimento (Rio-92), quando foram destacados os desafios de desenvolvimento do século

\footnotetext{
${ }^{7}$ Para maiores informações, consultar o site https://nacoesunidas.org/tema/odm/

${ }^{8}$ Para maiores informações, consultar o site https://nacoesunidas.org/pos2015/
} 
XXI, congregam a Agenda 2030 para governos locais e regionais promoverem uma sociedade mais igualitária e harmoniosa com a natureza.

Agora, estamos enfrentando um problema grave, que se constitui em emergência de saúde pública, de importância internacional. Trata-se do surgimento de um vírus que veio abalar as estruturas de uma sociedade tecnologicamente mais avançada do que era cem anos atrás, um evento externo ao movimento do capital, mas que o perturba diretamente quando se interrompem os fluxos de produção, consumo e financeiro. A crise pandêmica exige tomada de decisão para proteger vidas, socorrer os pequenos negócios e evitar o colapso do sistema de saúde.

A pandemia exacerba-se à medida que se globaliza mais rapidamente. Surgida na China, no fim de 2019, chega à Europa e aos EUA no início de 2020. No Brasil, precisamente em fevereiro de 2020. Passados seis meses, já atingiu todos os continentes, alcançando um total de mais de 213 países, segundo dados do Worldmeters (2020).

A Covid-19 colocou em xeque, sobretudo, todas as decisões políticas, econômicas e sociais tomadas anteriormente em favor dos planos de austeridade fiscal impostos pelo Estado no mundo inteiro, para atender aos ditames de um neoliberalismo exasperado, que "transformou o capitalismo, transformando profundamente as sociedades" (DARDOT; LAVAL, 2020, p. 9). Com o novo coronavírus, o que está em jogo é nada mais nada menos que a forma de atuação do Estado e a sua total subordinação ao mercado que ele tratou de abalar imediata e estruturalmente, ainda que sem um direcionamento planejado, pois a pandemia surgiu de forma rápida no mundo, agravando situações de recessão econômica em curso em alguns países, como, por exemplo, no Brasil, desde 2015-2016.

Essa crise pandêmica mostrou, sobretudo, a importância do sistema público de saúde, o único com maior capacidade de salvar vidas, sendo as doenças epidêmicas o seu foco (BARRY, 2020). Revelou, ademais, a importância dos programas de assistência social, das práticas sustentáveis de consumo, do respeito ao meio ambiente, da construção de uma infraestrutura urbana capaz de permitir o acesso mais igualitário a um sistema de transporte público de qualidade e seguro, saneamento básico, energia etc.

Tudo isso nos remete a pensar o nosso relacionamento com o mundo, a natureza, a sociedade e o Estado, no processo de reestruturação e transformação de um mundo mais sustentável ambientalmente, igualitário socialmente e sustentado economicamente. Contudo, a pandemia também revela a cruel veracidade de um mundo regido por práticas neoliberais há cerca de quarenta anos. O que isso significa? Valorização dos mercados financeiros, desvalorização das políticas de assistência social, anti-intervencionismo, destruição programada 
das regulamentações e instituições, direitos, regras, competição generalizada, modelo de mercado, o indivíduo perde sua condição de ser para tornar-se um ente que se comporta como uma empresa. São consequências dessa situação: individualização das relações sociais, polarização extrema entre ricos e pobres, austeridade fiscal, redução dos gastos públicos em áreas fundamentais para o enfrentamento de pandemias como saúde, educação, ciência e tecnologia, aumento do lucro no curto prazo, privatização, etc. (DARDOT; LAVAL, 2020).

O efeito de tudo isso se mostra claramente nas desigualdades sociais, na negação de parcela da sociedade que padece de problemas, os quais a pandemia ajuda a desnudar. É o caso, por exemplo, dos migrantes, que já convivem com a discriminação. $\mathrm{Na}$ pandemia, ela fica muito mais evidente, pois a doença também está associada a pessoas que vêm de fora (CALLEJA, 2020). Outra questão é o aumento do desemprego, condição que deixa transparecer a necessidade de alguns se sujeitarem a toda e qualquer relação de trabalho para não morrer de fome. Para estes, a quarentena não existe, é impraticável “[...], porque obriga os trabalhadores a escolher entre ganhar o pão diário ou ficar em casa e passar fome” (SANTOS, 2020, p. 17).

\section{A pandemia de Covid-19 e seus impactos mais severos}

Falar de impactos mais severos decorrentes da Covid-19 pode ser ainda muito cedo, mas não se pode negar que esse tipo de crise ocasiona efeitos devastadores, incluindo a perda de vidas e o caos econômico e social. Informações do GPMB (setembro de 2019) destacaram especialmente a possibilidade de situações de vulnerabilidade extrema, em decorrência do aumento de surtos em emergências humanitárias complexas. Poderá ocorrer também uma nova convergência de tendências ecológicas, políticas, econômicas e sociais, incluindo crescimento populacional, maior urbanização, economia globalmente integrada, viagens generalizadas e mais rápidas, conflitos, migração e alterações climáticas.

Para Furceri et al. (2020), as pandemias deixam em pior situação os segmentos mais pobres e vulneráveis da sociedade. De acordo com o referido estudo, os economistas já revelaram que a Covid-19 irá intensificar a desigualdade, sobretudo em razão do impacto desproporcional sobre os trabalhadores que possuem menor grau de qualificação.

Segundo os autores citados, as grandes epidemias do século XX elevaram a desigualdade de renda e causaram perda de expectativa de emprego por parte dos indivíduos que possuem apenas a formação básica, não afetando os trabalhadores com curso superior. Além do mais, de acordo com o acompanhamento dos efeitos distributivos nos cinco anos posteriores a cada 
ocorrência desses eventos epidêmicos, em 175 países, o coeficiente de Gini, um indicador da desigualdade, aumentou, em média, 1,5\%.

Riscos específicos podem ser apresentados, considerando os eventos dessa natureza ocorridos no mundo (GPMB, 2019, p. 13-15): i) perdas de vidas e caos econômico e social, sofrendo impacto maior as comunidades e populações mais vulneráveis; ii) vulnerabilidade econômica; iii) e impacto no comércio e no turismo, os quais representam cerca de $18 \%$ da economia global.

No caso da pandemia de Covid-19, a velocidade de contágio, os milhões de infectados e os impactos imediatos da doença, que deixam a atividade econômica quase paralisada pela imposição das restrições rígidas ao movimento para impedir a propagação do vírus, revelam um choque econômico imenso (WORD BANK, 2020a). Isso é tanto mais elevado quanto maior o número de óbitos e de infectados confirmados.

Informações do referido - The Global Economic Outlook During the Covid-19 Pandemic: A Changed World (WORD BANK, 2020a) - assinalam que a estimativa de contração da economia global já é de 5,2\%, em 2020, considerada, por esse meio, uma recessão global profunda jamais vista em décadas anteriores, a despeito dos esforços dos governos para atenuar/combater a recessão por meio de políticas fiscais e monetárias. Em longo prazo, informações do referido documento revelam impactos duradouros em razão dos baixos investimentos, erosão do capital humano por meio da perda de trabalho e de produtividade, bem como fragmentação dos vínculos comerciais e de fornecimentos globais.

Nas economias avançadas, as previsões do Word Bank indicam um encolhimento de 7\%. Essa reversão do crescimento econômico espalhar-se-á para as perspectivas de mercados emergentes e economias em desenvolvimento, que devem contrair 2,5\% quando enfrentarem seus próprios surtos domésticos do vírus. Isso representaria a exibição mais fraca desse grupo de economias em pelo menos sessenta anos (WORD BANK, 2020a).

Ademais, é esperado que essa crise reverta anos de progresso em direção aos objetivos de desenvolvimento no Leste e Sul da Ásia, na África Subsaariana, no Oriente Médio, no Norte da África, na Europa, Ásia Central e América Latina, levando dezenas de milhões de pessoas à extrema pobreza (WORD BANK, 2020b).

Segundo o estudo citado, os mercados emergentes e as economias em desenvolvimento serão afetados, especialmente pela pressão sobre os sistemas de saúde fracos, perda de comércio e turismo, remessas cada vez menores, fluxos de capital moderados e condições financeiras apertadas em meio à crescente dívida. Ademais, os exportadores de energia ou commodities industriais serão particularmente afetados. 
$\mathrm{Na}$ América Latina, especificamente, informações contidas no documento Global Economic Prospects do Word Bank (2020b) assinalam que os choques decorrentes da pandemia de Covid-19 poderão repercutir na queda da atividade econômica regional, cerca de 7,2\%, em 2020. No Brasil, espera-se um encolhimento em torno de 8\%, devido a bloqueios, investimentos em queda, interrupções na cadeia de suprimentos e baixos preços globais de commodities; no México, a contração econômica foi estimada em 7,5\%, em razão das restrições de financiamento, queda nos preços do petróleo, interrupção do turismo e restrições de mobilidade; na Argentina, em 7,3\%, refletindo medidas rigorosas de mitigação, menor demanda externa e os impactos da incerteza relacionados às negociações em andamento da dívida; na América Central, espera-se que a economia encolha 3,6\% e no Caribe 1,8\% e 3,1\%, excluindo a Guiana, onde a indústria de petróleo offshore está se desenvolvendo rapidamente.

Dito de outro forma, embora o resultado final ainda seja incerto, a pandemia de Covid-19 resultará em contrações na grande maioria dos mercados emergentes e nas economias em desenvolvimento bem como causará danos duradouros à produtividade do trabalho e à produção potencial (WORD BANK, 2020b). Desse modo, o referido documento mostra que as prioridades políticas imediatas são aliviar os custos humanos e atenuar as perdas econômicas de curto prazo. Contudo, depois que a crise diminuir, será necessário reafirmar um compromisso credível com políticas sustentáveis e empreender as reformas necessárias para sustentar as perspectivas de longo prazo, devendo, para tanto, buscar estabelecer a coordenação e cooperação globais, enfatiza o Banco Mundial.

Nesse sentido, estamos lidando com um vírus que não é democrático, pois, segundo Carvalho (2020), a pandemia está afetando especialmente os mais pobres, que sofrem com os impactos na saúde e na economia, os países com menor dotação de recursos para enfrentar a crise atual e aqueles que estão na base da pirâmide social, os quais tendem a desenvolver os casos mais graves da infecção por Covid-19, já que são obrigados a dividir o mesmo dormitório, transporte público e padecem com a falta de saneamento básico.

\section{Considerações finais}

A pandemia de Covid-19 configura-se como um desafio global, que exige uma profunda conscientização da população em geral sobre a necessidade de enfrentar o novo coronavírus com uma ampla discussão acerca do processo de enfrentamento da doença. O objetivo é evitar o colapso do sistema de saúde e atenuar os efeitos econômicos advindos das medidas que estão sendo corretamente implementadas para tentar reduzir o risco de infecção pelo vírus. 
Nesse contexto, a pandemia revela a crueldade de um capitalismo criado, transformado e remodelado para dar lugar ao novo mais industrializado, mais suntuoso, mais avançado, mais eficiente, cuja base consiste na valorização do capital em todos os aspectos do seu processo incessante de acumulação e reprodução da riqueza financeira oriunda do desenvolvimento do sistema financeiro no capitalismo globalizado.

A pandemia coloca em xeque justamente a importância dispensada a tudo aquilo que o capitalismo destruiu, em favor da dominação e do controle do espaço, da natureza física e da vida humana e animal do planeta. Isso porque o enfrentamento do novo coronavírus exigiu (e continua exigindo) um conjunto de medidas que estão sendo corretamente implementadas para tentar reduzir o risco de infecção e de contágio: isolamento social, quarentena e suspensão temporária do funcionamento das atividades consideradas não essenciais. É o caso dos shoppings centers, estabelecimentos comerciais, bares, restaurantes, áreas de lazer, serviços, instituições de ensino, entre outros, os quais foram obrigados a atender aos inúmeros decretos do poder público nacional, estadual e local, mundo afora.

\section{Referências}

BARRY, J. M. A Grande Gripe: A história da gripe espanhola, a pandemia mais mortal de todos os tempos. Rio de Janeiro: Editora Intrínseca LTDA. Edição digital: 2020.

CALLEJA, M. Covid-19 e o vírus que abalou o mundo. Portugal: Editora Oppian. Edição digital: 2020.

CARVALHO, L. Curto-Circuito: O vírus e a volta do Estado. São Paulo: Todavia. Edital digital: 2020.

DARDOT, P.; LAVAL, C. A nova razão do mundo: Ensaio sobre a sociedade neoliberal. São Paulo: Boitempo. Edição digital: 2020.

FURCERI, D.; LOUNGANI, P.; OSTRY, J. D. Como as pandemias deixam os pobres mais pobres. 11 Maio.2020. Disponível em:

https://www.imf.org/pt/News/Articles/2020/05/11/blog051120-how-pandemics-leave-the-pooreven-farther-behind?sc mode=1. Acesso em: 06 Jul.2020.

GPMB, Global Preparedness Monitoring Board. A word at risk: anual report on global preparedness for health emergencies. Geneva: World Health Organization, Set.2019.

HARVEY, D. O enigma do capital: e as crises do capitalismo. São Paulo, SP: Boitempo, 2011. . Espaços de esperança. $7^{\circ}$ ed. São Paulo: Edições Loyola, 2015.

NAÇÕES UNIDAS BRASIL. Os Objetivos de Desenvolvimento do Milênio. 2000. Disponível em: https://nacoesunidas.org/tema/odm/. Acesso em: 26 Jun.2020. 
NAÇÕES UNIDAS BRASIL. 17 Objetivos para transformar nosso mundo. 2015. Disponível em: https://nacoesunidas.org/pos2015/. Acesso em: 05 Jul.2020.

SANTOS, S. A cruel pedagogia do vírus. Coimbra: Edições Almedina S.A. Edição digital: 2020. SHEREEN, M. A.; KHAN, S.; KAZMI, A.; BASHIR, N.; SIDDIQUE, R. Covid-19 infection: Origin, transmission, and characteristics of human coronaviruses. Journal of Advanced Research, 24 (2020) 91-98. Disponível em: www.sciencedirect.com. Acesso em: 22 Abr.2020.

UJIVARI, S. C. Pandemias: A humanidade em risco. São Paulo: Contexto. Edição digital: 2011.

VEIGA, J. E. Desenvolvimento sustentável: o desafio do século XXI. Rio de Janeiro: Garamond, 2010.

WORD BANK. The Global Economic Outlook During the Covid-19 Pandemic: A Changed World. 08 Jun. 2020a. Disponível em:

https://www.worldbank.org/en/news/feature/2020/06/08/the-global-economic-outlook-duringthe-Covid-19-pandemic-a-changed-world. Acesso em: 05 Jul.2020.

. Global Economic Prospects. Latin America and the Caribbean. Jun.2020b. Disponível em: http://pubdocs.worldbank.org/en/538491588787962322/Global-Economic-Prospects-June2020-Analysis-LAC.pdf. Acesso em: 05 Jul. 2020.

WORLDOMETERS. Covid-19 Coronavirus Pandemic. 08 Jul.2020. Disponível em: <https://www.worldometers.info/coronavirus/> Acesso em: 08 Set.2020. 